Original Research Paper

\title{
Safe Ulvan Silver Nanoparticles Composite Films for Active Food Packaging
}

\author{
Hadear Hanie Amin \\ Department of Biochemistry, Faculty of Agriculture, \\ Ain Shams University, Shoubra EL-Khaima, Post number: 1241, P.O. Box: 68 Hadaeq Shubra, Cairo, Egypt
}

\author{
Article history \\ Received: 29-09-2020 \\ Revised: 25-01-2021 \\ Accepted: 25-01-2021 \\ Email: hadirhanie@hotmail.com \\ hadearhanie@agr.asu.edu.eg
}

\begin{abstract}
Protecting food from the corruption caused by different microbes is a big problem, as we need safe methods for food packaging. In this study, Ulvan (U), edible sulfated polysaccharide extracted from Ulva lactuca, was mediated for the first time non-toxic biosynthesized silver nanoparticles (Ag-NPs) to produce new and safe bio-nanocomposite films called (U/AgNPs) films for active food packaging. Ulvan was extracted by hot waterextraction and ethanol-precipitation method and was characterized by FTIR spectroscopy. Biosynthesis of silver nanoparticles using $U$. lactuca was proven by Ultra Violet-Visible (UV-VIS), Scanning Electron Microscope (SEM) and Transmission Electron Microscope (TEM) analyses. Investigation of films was by incorporation $1 \mathrm{~m} \mathrm{M}$ of $\mathrm{Ag}-\mathrm{NPs}$ into different concentrations of ulvan (3, 6 and $12 \%$, w/v). The formation of bionanocomposite films was confirmed by FTIR-ATR spectroscopy and TEM analysis. Bio-nanocomposite films were further characterized by physical parameters as water vapor permeability $(1.18 \pm 0.07,0.9 \pm 0.09$ and $0.55 \pm 0.1$ $\left.10^{-8} \mathrm{~g} \mathrm{~mm} \mathrm{~cm}^{-2} \mathrm{~h}^{-1} \mathrm{~Pa}^{-1}\right)$, film thickness $(0.01,0.03$ and $0.08 \mathrm{~mm})$ and contact angle measurements $\left(70.833^{\circ}, 81.066^{\circ}\right.$ and $\left.109.066^{\circ}\right)$ respectively. The bio-nanocomposite films also showed high antimicrobial activity using Kirby-Bauer method as antibacterial and good antioxidant activity with $\mathrm{IC}_{50}$ $=1.128 \mu \mathrm{g} / \mathrm{ml}$. (U/Ag-NPs) bio-nanocomposite films exhibited good chemical and physical properties, antioxidant and antimicrobial activities making them a potential substitute for active food packaging to extend shelf-life of foods during processing, transportation and storage with no harm as previous packaging methods.
\end{abstract}

Keywords: Ulvan Polysaccharides, Biosynthesized Silver Nanoparticles, Bio-Nanocomposite Films, Food Packaging, Antimicrobial Activity, Antioxidant Activity, Bio Nanotechnology

\section{Introduction}

Egypt had begun packaging food, as the ancient Egyptians had packed all their daily needs with their mummies and had produced paper from the papyrus plant to pack food such as vegetables and spices (Gupta et al., 2017). There are many considerations before designing a packaging method such as the interrelation between a food product and the packaging materials in stages of production, transportation, storage chains, environmental factors, price and customer acceptance (Gupta et al., 2017). Packaging is a method of separating food from abiotic factors such as moisture, gases, light and mechanical injuries and dust that cause food spoilage. It is an advanced science that not only protects color, taste and texture of products from production-to-mouth from damage, but also attracts customers towards the product. Packaging Materials are such as glass, plastic, aluminum, foils, tinplate and paper. It has been turned into active and intelligent packaging. Some of these packaging materials were harmful to human health. Packaging should act as a barrier against gases, microorganisms and oxidation by light. It should be costeffective, safe and made from available sources to save the food journey from deterioration. Active packaging plays an active role in food quality, as it is environmentfriendly and provides barriers to gases and oxidation by light on the surface of the food (Kumar and Thakur, 
2020). Bio-nanotechnology is part of the science of nanotechnology that will be used in food packaging, as it may contribute to enhance the quality of foods (Cano et al., 2018). Nanoparticles do their work through their chemical, physical and biological properties, because of their small size and large surface size compared to their large counterparts (Cano et al., 2018). Silver Nanoparticles (Ag-NPs) for their antimicrobial properties have further been used in many fields, in agriculture as nanopesticides (Amin, 2020a) in medicine such as bandages, tooth paste and anticancer (Amin and Abdelreheem, 2020) in food industries such as containers for food storage, air filters, cosmetic and paints (Cano et al., 2018). Ag-NPs enhance the film barrier properties, make the film stronger and increase the hydrophobicity of films, so bio-nanotechnology should be used in food packaging (Nile et al., 2020). Oceans and seas are rich in algae which had been used as human food in many countries in the world especially in Asia and have a major role in the industry such as fertilizer, biofuels and pesticides (Yu-Qing et al., 2016) as animal feed (Abd El-Galil and Amin, 2017) in medicine as anti-tumor drugs (Amin et al., 2015) and in the food processing industry products such as fish balls, meatballs, nuggets, broad bean beans and cooked horse beans (Meshhal, 2018). U. lactuca is a green macro alga that is called green lavers or sea lettuce is characterized by many beneficial phytochemicals (Amin, 2019) and is also characterized by polysaccharides that show good anti-microbial and antioxidants activities (Amin, 2020b) Its polysaccharides have a unique chemical structure that can't be found in higher plants or other algae called ulvan and is used in medicine for fighting many diseases ( $\mathrm{Yu}-$ Qing et al., 2016) such as against cancer (Amin and Abdelreheem, 2020), in the bio-control activity of many microbes (Rivas-Garcia et al., 2018) and is also used as prebiotic in food industry (Shalaby and Amin, 2019) and in food packaging (Guidara et al., 2020). Biopolymers such as polysaccharide, ulvan, are biocompatible, biodegradable, non-toxic, highly stable and safe for use in the food packaging industry and delivery of nutraceutical products (Ahmed and Ali, 2020). Plants or algae are used for the biosynthesis of nanoparticles, as a reducing agent by bottom-up reaction. It is inexpensive, non-toxic and eco-friendly (Amin, 2020a). For this reason the biosynthesis of silver nanoparticles using algae should be applied in food packaging to achieve safe bio-nanocomposite films (Cano et al., 2018). AgNPs were incorporated into the casings of cellulose sausage and collagen and showed good antibacterial activity (Cano et al., 2018). Ag-NPs were mediated starch films for packaging and exhibited good antimicrobial against foodborne pathogens (Abreu et al., 2015). Ag-NPs were also incorporated into cellulose nanocomposite films and used in active food packaging for its bactericidal activity (Moura et al., 2012). Using Ag-NPs for bionanocomposite films showed significant antibacterial properties against Escherichia coli and $S$. aureus bacteria (Oliani et al., 2016). Ag-NPs were added with polyethylene and showed good microbial control and lengthen the shelf life of chicken breast fillets (Azlin-Hasim et al., 2015). Methylcellulose films with Ag - NPs showed excellent antimicrobial and antioxidant activities against $S$. aureus and $E$. coli. The incorporation of Ag-NPs improved the hydrophobicity of produced films (Nunes et al., 2018). The incorporation of active nanoparticles into polysaccharides caused good physical properties, antioxidant and antimicrobial properties of the food packaging materials (Nile et al., 2020). A composite is a material that consists of more than one compound to increase the activity of materials by combining with other materials (Ahmed and Ali, 2020). The film fabricated from the polysaccharide only has poor water vapor barrier properties due to its hydrophilic nature, but this disadvantage improved by the incorporation of other nanoparticles (Ahmed and Ali, 2020). In this study, new, cheap, eco-friendly and non-toxic bionanocomposite films were made for the first time from edible marine sulfated polysaccharides, ulvan which mediated with safe green synthesized silver nanoparticles. These films exhibit good physical and chemical properties and also have antioxidants and antimicrobials activities against many gram positive and gram negative bacteria that cause deterioration of packaged food. Bio-polymer nanocomposite films should be used in active food packaging to increase the shelf life of packaged foods, food safety and food quality without harm, as it will be a good challenge to overcome environmental risk that was caused by previous packaging methods.

\section{Materials and Methods}

\section{Materials}

Silver Nitrate $\left(\mathrm{AgNO}_{3}\right)$ was bought from Morgan Specialty Chemicals in Egypt.

Fresh $U$. lactuca samples were gotten during the spring of 2018 from The Abu Qir coast, Mediterranean Sea, Alexandria, Egypt.

\section{Methods}

(U/ Ag-NPs) bio- nanocomposite films were developed by ulvan, sulfated polysaccharides extracted from $U$. lactuca, mediated with biosynthesized silver nanoparticles, using also U. lactuca, then characterized of extracted ulvan, biosynthesized silver nanoparticles and formed films were done. Antimicrobial and antioxidant activities of films were investigated as in the following (Scheme 1). 


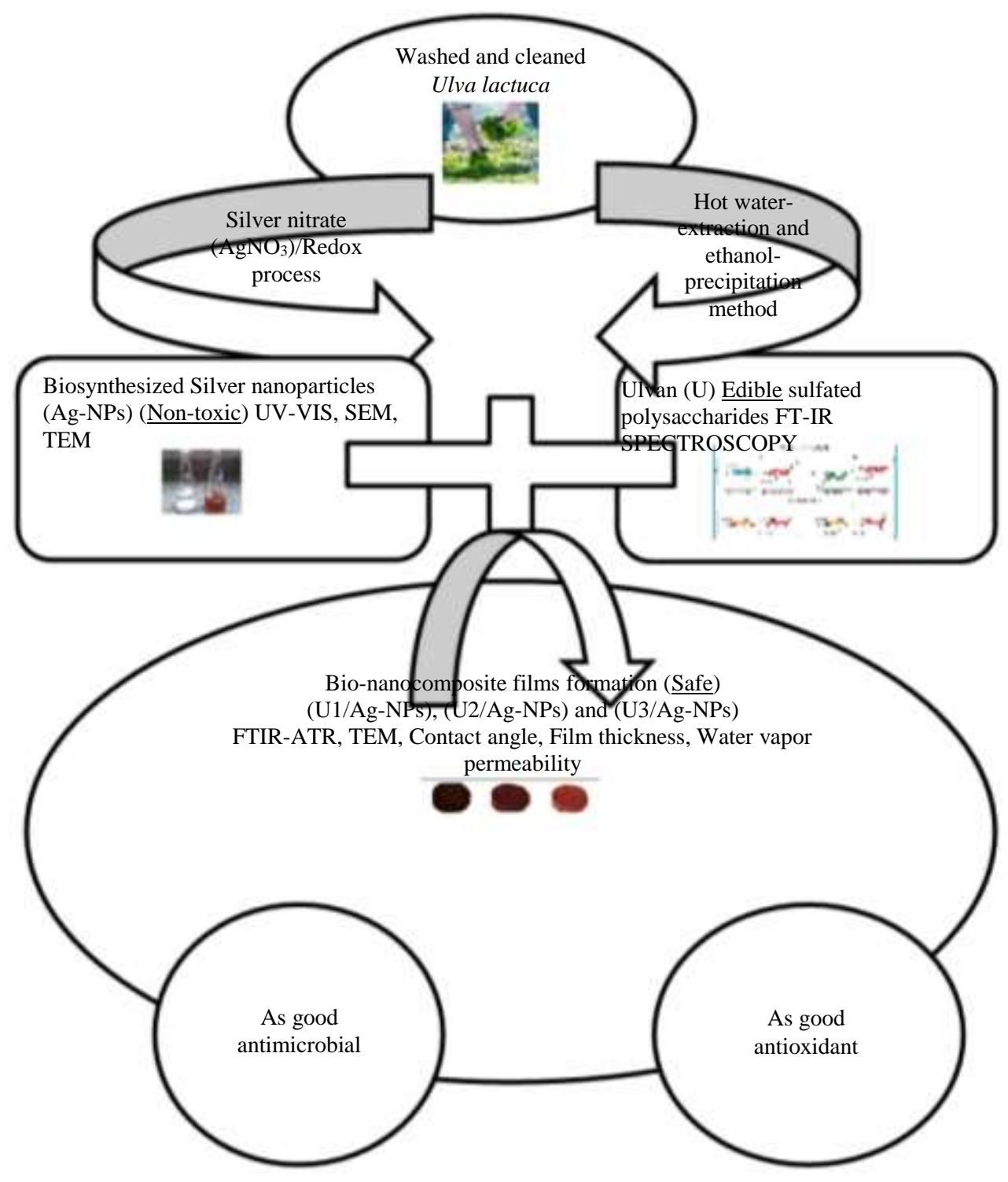

Scheme 1: Plan of the research work

\section{Extraction of Ulvan Polysaccharide from U. lactuca}

Fresh samples of $U$. lactuca were washed and cleaned with a diluted sodium chloride solution to remove any contaminants. The cleaned seaweed samples were dried, crushed and grounded in an electric blender to form a powder and stored in the refrigerator as recorded by (Amin, 2019). Ulvan polysaccharide was extracted by the modified procedure of (Hussein et al., 2015) using the methods of hot water-extraction and ethanolprecipitation. $100 \mathrm{~g}$ of dried U. lactuca were extracted three times at $100^{\circ} \mathrm{C}$ for $2 \mathrm{~h}$ with double-distilled water, after the collected extracts were centrifuged for $15 \mathrm{~min}$ at $6000 \mathrm{rpm}$; then the extracts were precipitated using ethanol and the mixture was kept in the refrigerator overnight. Finally, precipitates were obtained by centrifugation at $6000 \mathrm{rpm} 15 \mathrm{~min}$, dialyzed against deionized water for $72 \mathrm{~h}$ towards removing traces of the alcohol, freeze-dried to yield ulvan polysaccharide that its touch and appearance were like gel.

The yield of polysaccharide $(\%)$ was calculated by the following equation as described in (Amin, 2020b) and (Shalaby and Amin 2019):

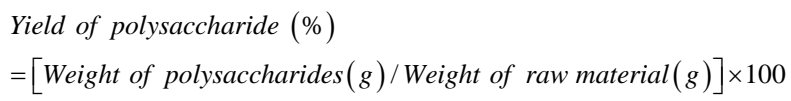

The sulfate content of ulvan was measured using Ion Chromatography (ICS-1100-Thermo Dionex, USA) in the central laboratory of the faculty of Science, Ain Shams University, Egypt. 
Biosynthesis of Silver Nanoparticles (Ag-NPs) using $U$. lactuca

$10 \mathrm{~mL}$ of aqueous extract of the alga $(10 \mathrm{~g}$ of the alga were added to $100 \mathrm{~mL}$ of distilled water, centrifuged for $1 \mathrm{~h}$ at 6,000 rpm and the extracts kept in the refrigerator (Amin, 2019) were added to $1 \mathrm{mM}$ of silver nitrate stirred for $24 \mathrm{~h}$ at $100^{\circ} \mathrm{C}$. The reaction color changed from transparent to brown that indicated the success of the reaction (Amin, 2020a).

\section{Preparation of Bio-Nanocomposite Films}

$1 \mathrm{~m} \mathrm{M}$ of Ag-NPs was incorporated into different concentrations of ulvan polysaccharides $(3,6$ or $12 \%$, w/v) (gs of ulvan in $100 \mathrm{~mL}$ of Ag-NPs), mixed and left to be stirred overnight. Then all formed films were poured into a $18 \mathrm{~cm}$ circular Teflon surface for film formation. Then plates were then kept at laboratory temperature for drying for three days, placed in an oven at $25^{\circ} \mathrm{C}$ for additional two days. After drying, the formed films were kept in plastic bags and stored at laboratory temperature.

The formed films were three (U1/Ag-NPs), (U2/AgNPs) and (U3/Ag-NPs) where:

$$
\begin{aligned}
& U 1=3 \mathrm{~g} \text { of ulvan, } U 2=6 \mathrm{~g} \text { of ulvan and } U 3 \\
& =12 \mathrm{~g} \text { of ulvan,but } \mathrm{Ag}-N P \mathrm{~N}=1.0 \mathrm{mM}
\end{aligned}
$$

\section{Ultra Violet-Visible (UV-VIS) Spectroscopy Analysis}

Ultra Violet-Visible was applied to prove the formation of silver nanoparticles (Fig. 1).

UV-VIS was done by Schimatzu UV-1800 at the central laboratory at, Ain Shams University, Egypt.

Scanning Electron Microscope (SEM) and Transmission Electron Microscope (TEM)

Shape and size of formed nanoparticles and the success of the formation of biosynthesized Ag-NPs were done at the National Research Center (NRC), Egypt (Fig. $2 a$ and $2 b$ ), while TEM of bio- nanocomposite films was also done at the same place (Fig. 2c).

SEM was determined at an applied potential of 15 $\mathrm{kV}$, but samples of TEM were achieved by placing two drops of Ag-NPs solution or film into carbon-coated TEM grids and dried before measurement.

Fourier-Transform Infrared (FT-IR) of Ulvan Polysaccharides and Fourier-Transform InfraredAttenuated Total Reflection (FTIR-ATR) of BioNano Composite Films

Active groups of ulvan were determined in the wavelength interval of 4000 to $400 \mathrm{~cm}^{-1}$ in the central laboratory at Ain Shams University, Egypt (Fig. 3a), but FTIR-ATR of bio-nanocomposite films was measured in the range $4000-400 \mathrm{~cm}^{-1}$ using Bruker VERTEX $80 / 80 \mathrm{v}$
FT-IR spectrometers at the National Research Center (NRC), Egypt (Fig. 3b).

\section{Film Characterization (Table 1)}

Film Thickness was measured and calculated at the National Research Center (NRC), Egypt using a Digital Micrometer at 6 Random Positions of the Film (Guidara et al., 2020).

Water Vapor Permeability (WVP) was done at (NRC), Egypt. (WVP) was determined by gravimetric method based on (Casariego et al., 2009) procedures. Three dried films were put on top of cups containing 50 $\mathrm{mL}$ of distilled water, sealed and then weight loss overtime till steady state was recorded. Water Vapor Transmission Rate (WVTR) was calculated using the linear regression analysis and WVP $10^{-8} \mathrm{~g} \mathrm{~mm} \mathrm{~cm}^{-2} \mathrm{~h}^{-1}$ $\mathrm{Pa}^{-1}$ was obtained as follows:

$$
W V P=(W V T R / \triangle P) * Y
$$

Where, $P=$ pressure $/ Y=$ film thickness $/ W V T R=$ Water Vapor Rate.

Contact angle (the surface polarity) was measured and calculated at (NRC), Egypt by The Young-Laplace method. Replicates of one drop of $3 \mu \mathrm{L}$ was placed on the surface of each film then the contact angle was achieved using the shape of the drop, according to the following: $\theta$ $=2 \tan ^{-1}(2 \mathrm{~h} / \mathrm{d})$, where $(h$ and $d)$ are the height and diameter of the water drop (Abreu et al., 2015).

\section{Antioxidant Activity of Bio-Nanocomposite Films}

Adding 100, 200, 300, 400, 500, 600, 700, 800, 900, $1000 \mu \mathrm{L}$ of film of (U3/Ag-NPS) were placed in tubes and raised each solution in each tube to $1 \mathrm{ml}$ by adding ethanol and $4 \mathrm{~mL}$ of DPPH were also added to each tube (Shalaby and Amin, 2018) incubated for $30 \mathrm{~min}$. at laboratory temperature in the dark, the absorbance was read against the blank at $517 \mathrm{~nm}$. Antioxidant activity of bio-nanocomposite films was calculated according to the following equation:

$$
\begin{aligned}
& \% \text { scavenging activity } \\
& =(A \text { control }-(A \text { sample } / A \text { control })) \times 100
\end{aligned}
$$

\section{Antimicrobial Activity of Bio-Nanocomposite Films} by Kirby-Bauer Method

Antimicrobial activity was determined by a modified Kirby-Bauer disc diffusion method (Bauer, 1966) 100 $\mu \mathrm{L}$ of the tested bacteria was grown in suitable media (Pfaller et al., 1988) then $100 \mu \mathrm{L}$ of bacterial suspension was spread onto agar plates (National Committee for Clinical Laboratory Standards, 1993a) recommended Mueller-Hinton agar. Disc diffusion method was recommended for yeasts (National Committee for 
Clinical Laboratory Standards, 2003). The Gramnegative bacteria Desulfomonas pigra ATCC 29098T were inoculated and incubated for $24-48 \mathrm{~h}$ and the diameters of the inhibition zones were measured in millimeters (Bauer, 1966) Ampicillin (Antibacterial agent) was used as positive controls, but DMSO was used as negative control. Then zone diameters were measured as mentioned in (National Committee for Clinical Laboratory Standards, 1993b). Agar-based methods as disk diffusion can be good alternatives because they are simple and fast methods (Liebowitz et al., 2001; Matar et al., 2003) Table 2 as described in (Amin, 2019; Amin, 2020a; 2020b).

\section{Statistical Analysis}

SPSS (version 20) was used for statistical analysis. The propit analysis was used to calculate the medium Effective Concentration $\left(\mathrm{EC}_{50}\right)$ for determining bactericidal activity and the medium inhibition concentration $\left(\mathrm{IC}_{50}\right)$ to determine the antioxidant activity. Duncan's multiple range was also used to separate among three concentrations at $\mathrm{P} \leq 0.05$ in all physical parameters (Francis et al., 2006).

\section{Results and Discussion}

\section{Ulvan Characterization}

$U$. lactuca is a green macro alga characterized by sulfated polysaccharides called ulvan that is not found in any other alga or higher plants at all. It is composed of iduronic acid, glucouronic acid, sulfate, xylose and rhamnose (Lahaye and Robic 2007). Its yield was $5: 10 / 100 \mathrm{~g}$ of dry weight of the alga, its sulfate content was $3.998 \%$ (Shalaby and Amin 2019) and the functional groups of ulvan were determined by FT-IR spectroscopy (Fig. 3a) (Amin, 2020b).

\section{Characterization of Biosynthesized Silver Nanoparticles (Ag-NPs)}

Characterization of biosynthesized silver nanoparticles was achieved by UV-VIS, SEM and TEM analyses. The absorption spectrum of UV-VIS was shown at $446 \mathrm{~nm}$ (Fig. 1), this was due to the surface Plasmon of formed silver nanoparticles that also proved the success of the reaction (Khalifa et al., 2016). The SEM proved the spherical shape of silver nanoparticles with an average size of 3.89:55 nm (Fig. 2a) and the formation of biosynthesized silver nanoparticles was proved by TEM (Fig. 2b), but the success of bio-nanocomposite films formation was also proved by TEM (Fig. 2c).

\section{FT-IR Spectra of Ulvan and FTIR-ATR of Bio- Nanocomposite Films Analyses}

FT-IR spectra of ulvan, indicated its chemical composition and the functional groups of it as illustrated in (Fig. 3a), but FTIR-ATR of bio-nanocomposite films (Fig. 3b) confirmed the success of bio-nanocomposite films formation. Peaks (3419.75 and $3799.11 \mathrm{~cm}^{-1}$ ) of $\mathrm{O}-\mathrm{H}$ stretch of ulvan in (Fig. 3a) have completely disappeared at $\left(3799.11 \mathrm{~cm}^{-1}\right)$, but have been diminished at $\left(3419.75 \mathrm{~cm}^{-1}\right)$ in bio-nanocomposite films (Fig. 3b).

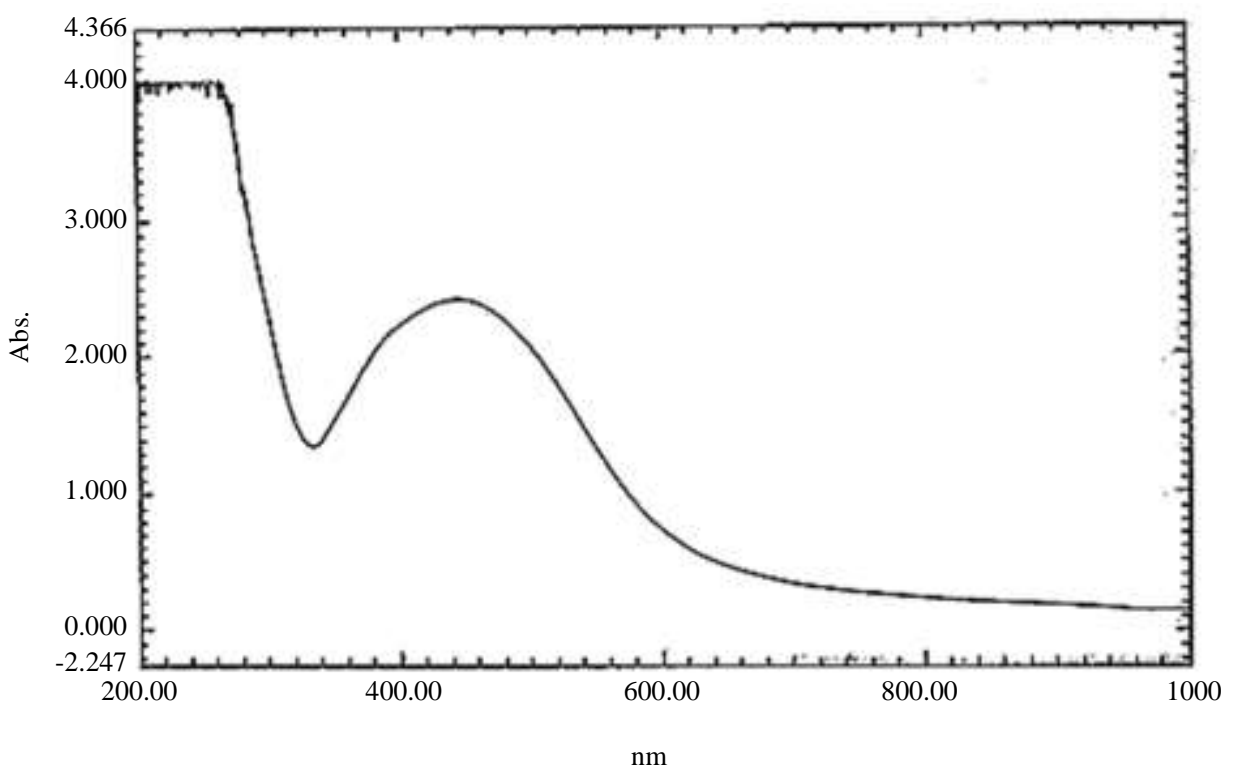

Fig. 1: Ultra violet-visible analysis of Ag-NPs 


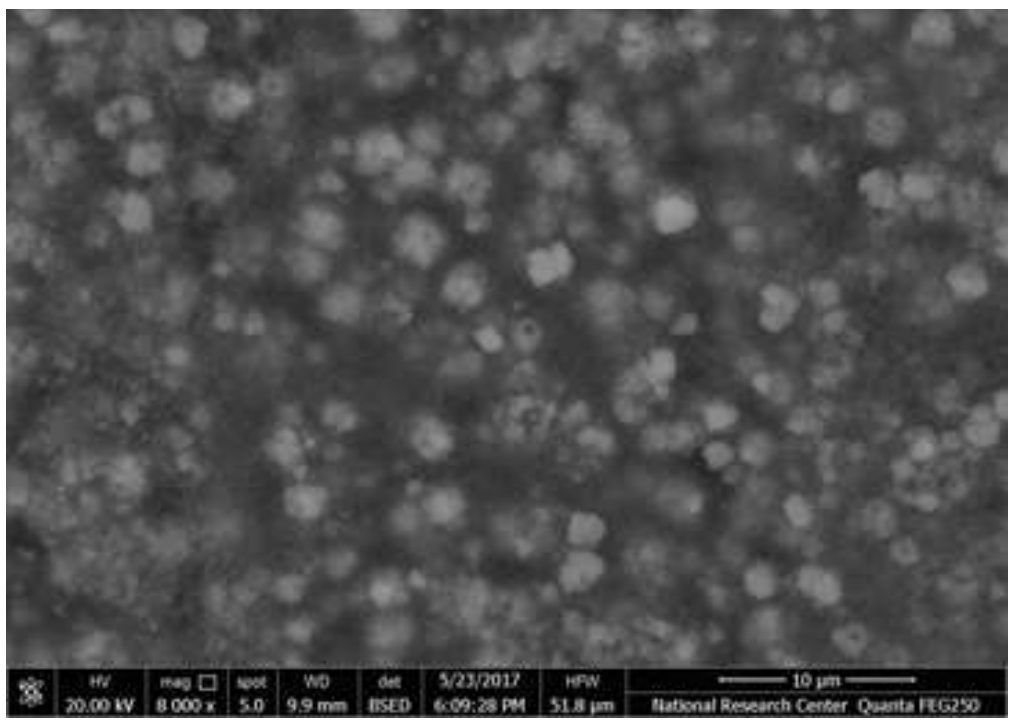

(a)

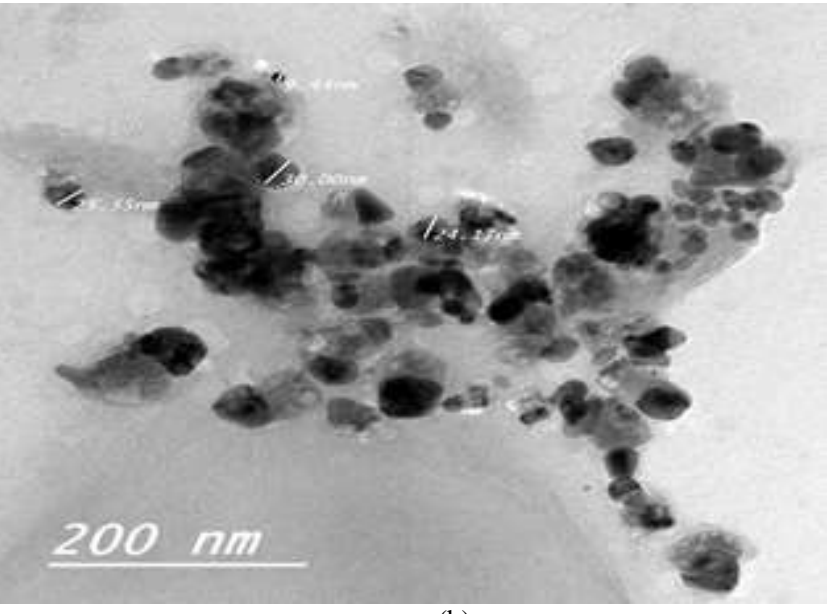

(b)

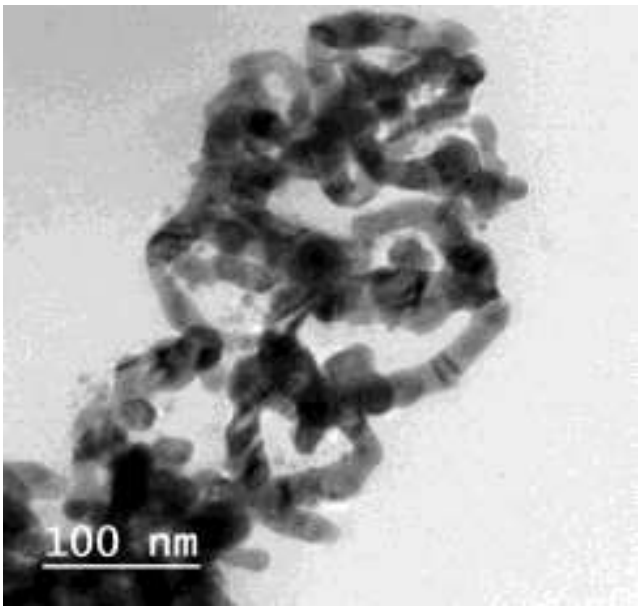

(c)

Fig. 2: (a) SEM Micrograph of Ag-NPs (b) TEM Micrograph of Ag-NPs (c) TEM Micrograph of bio-nanocomposite film

Peaks (1657.27 and $\left.1733.03 \mathrm{~cm}^{-1}\right)$ of -COO- stretch of uronic acid, peaks (1406.01 and $\left.1462.33 \mathrm{~cm}^{-1}\right)$ of symmetric stretch of - COO- and stretch of C-O within $\mathrm{COOH}$, peaks $\left(1275.26 \mathrm{~cm}^{-1}\right)$ of a sulfate group, peaks (1099.44, 1123.89, 1185.02, 1041.8 and $1076.72 \mathrm{~cm}^{-1}$ ) of the region of ring vibrations overlapped with stretching vibrations of $(\mathrm{C}-\mathrm{OH})$ side groups and the $(\mathrm{C}$ O-C) glycosidic bond vibrations, peaks (837.41 and $894.03 \mathrm{~cm}^{-1}$ ) of $\alpha$-dominating configuration of the sugar units sulfate ester and peaks (499.66, 528.34, 709.18 and $731.17 \mathrm{~cm}^{-1}$ ) of indicated sulfate ester groups (C-S-O) in the axial of ether and equatorial primary sulfate group and S-O of sulfate group are present in FT-IR of ulvan (Fig. 3a) and at the same time in all formed bionanocomposite films in (Fig. 3b), but peaks were partially diminished in all formed bio-nanocomposite films (Fig. 3b). This may be due to the attraction between the nucleophile oxygen of $(\mathrm{O}-\mathrm{H},-\mathrm{COO}-, \mathrm{C}-\mathrm{OH}$, $\mathrm{C}-\mathrm{S}-\mathrm{O}$ and $\mathrm{S}-\mathrm{O}$ ) and the functionalized surface of the electrophile silver nanoparticle. The higher the sulfated polysaccharide ulvan concentrations, the more biosynthesized silver nanoparticles are bound to the functional groups of polysaccharides ulvan. From FTIRATR of bio-nanocomposite films and FT-IR of ulvan was indicated that Ag-NPs is a good electrophile and react with nucleophile oxygen of both hydroxyl, carboxyl and sulfate groups of ulvan. Finally, FTIRATR should indicate the interaction between sulfated polysaccharides ulvan and biosynthesized silver nanoparticles through the functional groups of ulvan and indicated also the success of bio-nanocomposite films formation (Moura et al., 2012); (Amin, 2020b). 
Hadear Hanie Amin / American Journal of Biochemistry and Biotechnology 2021, 17 (1): 28.39

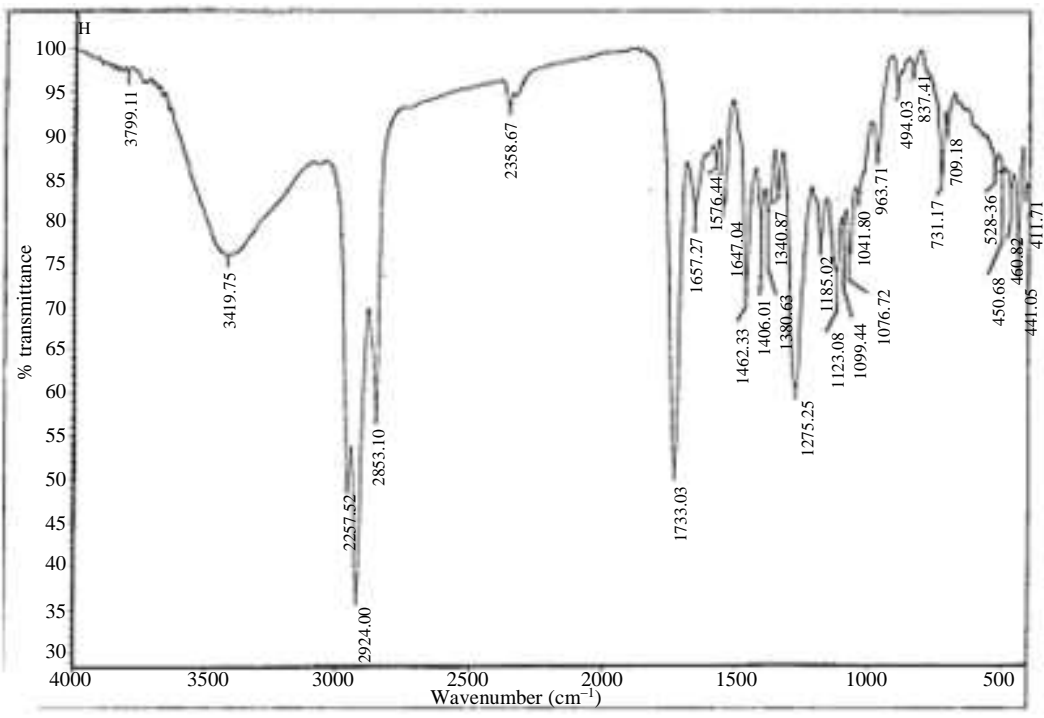

(a)

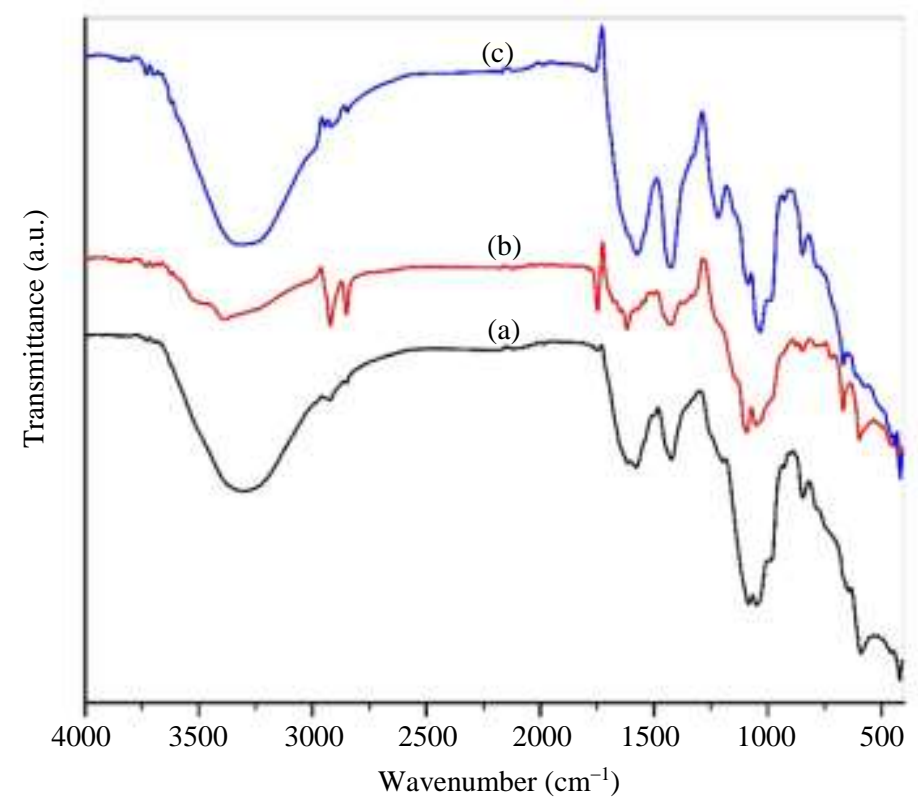

(b)

Fig. 3: (a) FT-TR spectrum of ulvan (b) FTIR- ATR analysis of bio-nanocomposite films; Where films (a) = film of (U2/Ag-NPs), (b) = film of (U3/Ag-NPs), (c) = film of (U1/Ag-NPs)

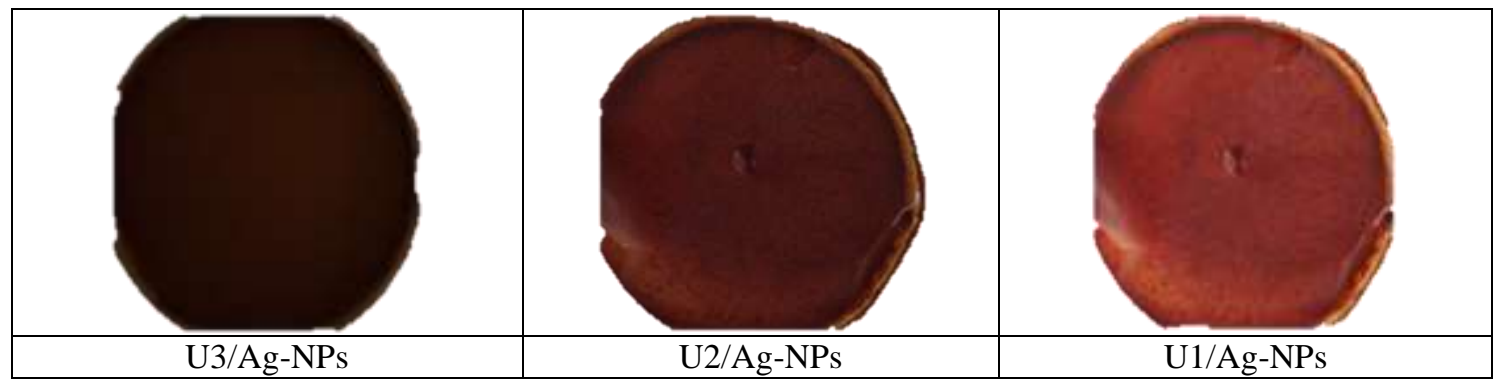

Fig. 4: Films appearance 


\section{Films Appearance (Fig. 4)}

\section{Film Thickness of Formed Bio-Nanocomposite Films}

As illustrated in (Table 1) the higher the polysaccharide concentration of the formed bionanocomposite films, the greater the thickness of the films and therefore, the greater the thickness of the films, the greater resistance to gases permeability of films (Guidara et al., 2020).

\section{Barrier to Water Vapor Permeability (WVP)}

Packaging materials with barrier gases property is a good function of food packaging and can extend shelf-life and food quality of packaged foods. Results of (WVP) of formed bio-nanocomposite films were put in Table 1.

The results indicated that the films showed low WVP values (0.55 to $1.1810^{-8} \mathrm{~g} \mathrm{~mm} \mathrm{~cm}^{-2} \mathrm{~h}^{-1} \mathrm{pa}^{-1}$ ) these WVP values were lower than WVP values of films of kappa carrageenan, (from 3.26 to $4.3210^{-8} \mathrm{~g} \mathrm{~mm} \mathrm{~cm}^{-2}$ $\mathrm{h}^{-1} \mathrm{pa}^{-1}$ ) and also less than ulvan films (from 1.28 to $4.4010^{-8} \mathrm{~g} \mathrm{~mm} \mathrm{~cm}^{-2} \mathrm{~h}^{-1} \mathrm{pa}^{-1}$ ) as mentioned in (Guidara et al., 2020), but those later films of semirefined kappa carrageenan and ulvan in (Guidara et al., 2020) were in the presence of plasticizers, as the concentration of plasticizers increased, the water vapor permeability increased and both of them mentioned that the plasticizers can penetrate the polymer of polysaccharide, diminish polymer's matrix, cause the mobility of polymer of polysaccharide and increase the empty volume of the formed film. Thus, it allows water molecules to diffuse easily, leading to high values of WVP (Guidara et al., 2020). On the other hand incorporation of silver nanoparticles into films of cellulose reduce WVP from (0.8 (Hydroxypropyl Methylcellulose (HPMC) film with no particles of $\mathrm{Ag}$ NPs): 0.556 (Hydroxypropyl methylcellulose (HPMC) film with $100 \mathrm{~nm}$ size of Ag-NPs): 0.48 ((Hydroxypropyl methylcellulose (HPMC) film with 41 $\mathrm{nm}$ size of Ag-NPs)) (g mm K ${ }^{-1} \mathrm{~Pa}^{-1} \mathrm{~h}^{-1} \mathrm{~m}^{-2}$ ) as obtained in (Moura et al., 2012) and also from $(1.34 \pm 0.20$ for starch films only to $(1.30 \pm 0.16)$ for $(\mathrm{Ag}-$ NPs/Starch $(0.3 \mathrm{mM} \mathrm{Ag}))$ and $(1.12 \pm 0.20)$ for $(\mathrm{Ag}-$ $\mathrm{NPs} /$ Starch $(1.0 \mathrm{mM} \mathrm{Ag}))$, but $(1.15 \pm 0.19)$ for (C30B/ST-NC (Clay/Starch films)) to $(1.01 \pm 0.21$ for (Ag-NPs/C30B/Starch $(0.3 \mathrm{mM} \mathrm{Ag}))$ and $(0.90 \pm 0.33)$ for $(\mathrm{Ag}-\mathrm{NPs} / \mathrm{C} 30 \mathrm{~B} / \mathrm{Starch}(1.0 \mathrm{mM} \mathrm{Ag}))\left(\mathrm{g} / \mathrm{m} \mathrm{s} \mathrm{Pa} \times 10^{10}\right)$ as investigated in (Abreu et al., 2015). So in this article WVP values were lower than were investigated in (Guidara et al., 2020), but were similar to those obtained in (Abreu et al., 2015; Moura et al., 2012). (WVP) is one of the most important characteristics of formed bio-nanocomposite films. Polysaccharide films are fairly poor water barriers, because of their hydrophilic nature, but adding biosynthesized (Ag-NPs) has a good effect on WVP values of films as shown in Table 1 where these particles can increase the hydrophobicity of formed films and work as an excellent gas barrier and thus increase the food quality, as the higher the polysaccharide concentration, the more biosynthesized silver nanoparticles are bound to the functional groups of sulfated polysaccharides ulvan and thus the hydrophobicity is increased, as functional groups are excellent for metal complexation as shown in Table 1. The small size of nanoparticles manages them to occupy the free spaces of the polymer and causes resistance to water diffusion into the film, thus Ag-NPs reduced the intermolecular spacing within the formed films as well as reduce the WVP through formed films (Abreu et al., 2015; Moura et al., 2012) and that is matched with results of SEM of this article. The sizes of nanoparticles of this article were small from 3.89:55 nm as mentioned in Fig. $2 \mathrm{a}$ and that helps to occupy the spaces of ulvan polysaccharides, increase the hydrophobicity of bionanocomposite films, reduce WVP values, improve and enhance the resistance of gases.

\section{Contact Angle of Formed Bio-Nanocomposite Films}

As illustrated in (Table 1), the greater the polysaccharide concentration of bio-nanocomposite films, the greater the contact angle where the contact angle above $65^{\circ}$ is used as an indication of the surface hydrophobicity of formed films, so all formed films showed contact angles above $65^{\circ}$ and indicate a good function of hydrophobicity. The hydrophobicity of films is sure due to silver nanoparticles, because polysaccharides are poor hydrophobic. The higher the polysaccharide concentration, the more biosynthesized silver nanoparticles are bound to the functional groups of polysaccharides ulvan and thus non-polarity is increased (Moura et al., 2012).

Antioxidant activity of (U3/Ag-NPs) bionanocomposite film was at a concentration $(94 \mu \mathrm{L}$ of the film) with $\mathrm{IC}_{50}=1.128 \mu \mathrm{g} / \mathrm{mL}$. The bio-nanocomposite film showed a good antioxidant activity at low concentrations, because both Ag-NPs and ulvan are effective as antioxidants (Amin, 2020a; 2020b). This is a good indication of the use of these films to package foodstuffs to protect packaged foods against light, radiation, ozone, oxygen and any other effects that cause oxidation and thus enhance the shelf life of packaged foods.

\section{Antimicrobial Activity of Bio-Nanocomposite Film (U3/Ag-NPs) (Fig. 5)}

Many epidemiological studies illustrated that foodrelated diseases are caused by pathogenic microorganisms and this prompts researchers to search to control them. Film (U3/Ag-NPs) exhibit good antibacterial at a small concentration $(10 \mu \mathrm{l} / \mathrm{disk})$ as 
mentioned in Table 2, since all tested bacteria attack packaged meat, vegetables, fish, fruits, poultry and dairy products. Ag-NPs are characterized by their small size which enables them to penetrate the cell wall of bacteria and disturb the permeability of the cell wall by interacting with sulfur and phosphorous of DNA, RNA, protein and may be cofactors of enzymes and cause damages to cell walls of bacteria, especially that done at greater surface ratios to the size of its reaction. Thus Ag-NPs inhibit the reproduction of bacteria and cause cell death (Amin, 2020a). On the other hand, the antimicrobial activity of the bio-nanocomposite films increased with increasing concentrations of ulvan, as sulfate groups of ulvan may also be responsible for the antimicrobial activity of bio-nanocomposite films (Amin, 2020b).
Both Ag-NPs and ulvan are effective as antimicrobial agents (Amin, 2020a; 2020b), so bio-nanocomposite films were more effective as antimicrobial agents. Packaging films that possess antimicrobial and antioxidant activities will be preferably used to control the deterioration of packaged foods caused by microbes and will have a good effect on prolonging the shelf-life of packaged foods. Since biosynthesized silver nanoparticles Ag-NPs have antimicrobial properties with no toxicity. It can also be worked as good gases barriers in food packaging; we should develop bio-based polysaccharides mediated with silver nanoparticles nanocomposite films for food packaging with antimicrobial and antioxidant activities. (Abreu et al., 2015; Moura et al., 2012).
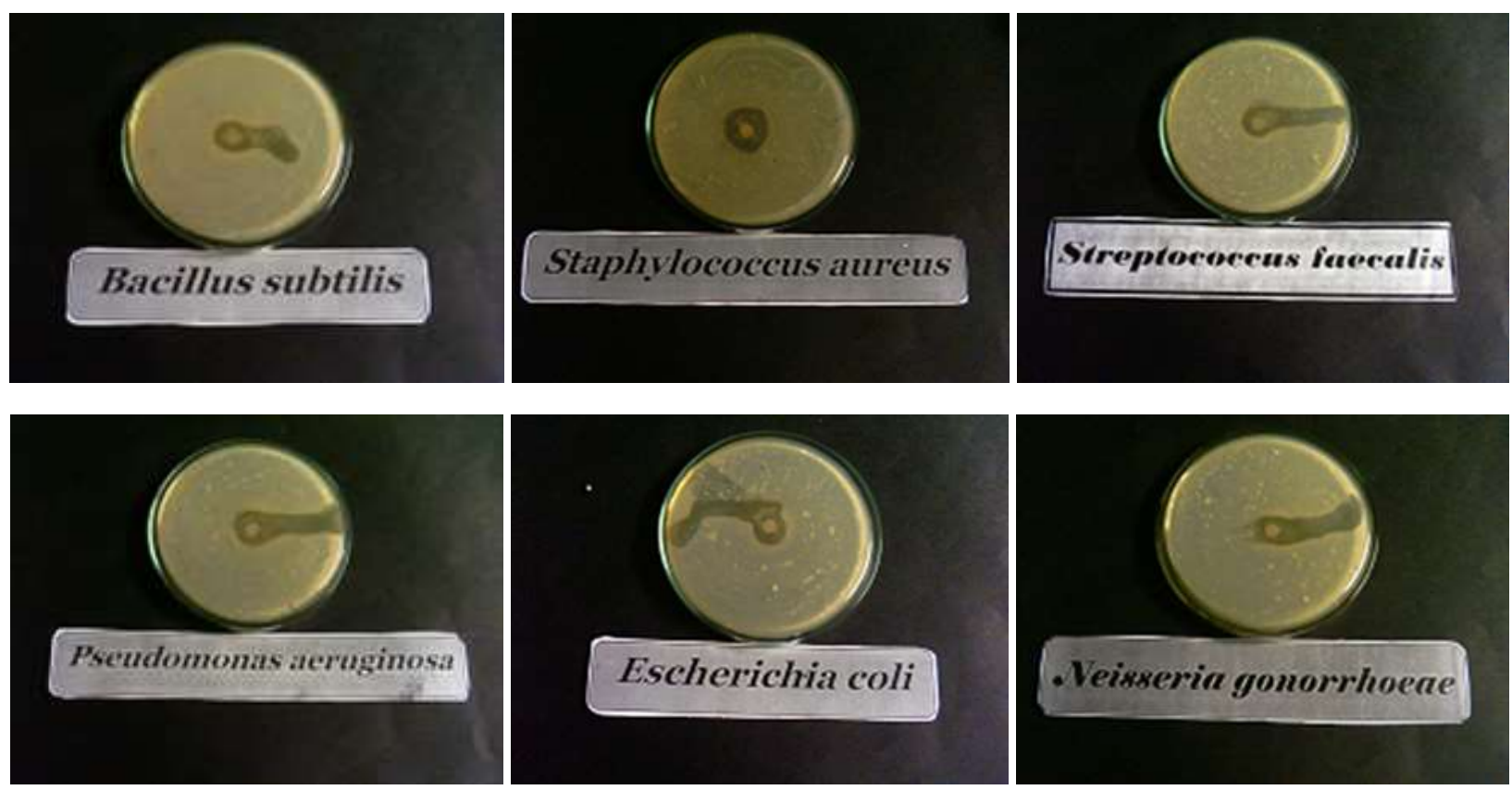

Fig. 5: Antimicrobial activity of (U3/Ag-NPs) bio-nanocomposite film

Table 1: Physical properties of films

\begin{tabular}{|c|c|c|c|}
\hline \multirow[b]{2}{*}{ Physical property } & \multicolumn{3}{|l|}{ The film } \\
\hline & U1/Ag-NPs & U2/Ag-NPs & U3/Ag-NPs \\
\hline Contact angle & $70.833^{\circ \mathrm{c}}$ & $81.066^{\circ \mathrm{b}}$ & $109.066^{\circ a}$ \\
\hline Film thickness $(\mathrm{mm})$ & $0.01 \pm 0.006 \mathrm{~mm}^{\mathrm{c}}$ & $0.03 \pm 0.006 \mathrm{~mm}^{\mathrm{b}}$ & $0.08 \pm 0.006 \mathrm{~mm}^{\mathrm{a}}$ \\
\hline Water vapor permeability $\left(10^{-8} \mathrm{~g} \mathrm{~mm} \mathrm{~cm}^{-2} \mathrm{~h}^{-1} \mathrm{pa}^{-1}\right)$ & $1.18 \pm 0.07^{\mathrm{c}}$ & $0.9 \pm 0.09^{\mathrm{b}}$ & $0.55 \pm 0.1^{\mathrm{a}}$ \\
\hline
\end{tabular}

Table 2: Antimicrobial activity of (U3/Ag-NPs) bio-nanocomposite film

\begin{tabular}{llll}
\hline Inhibition zone diameter $(\mathrm{mm} / \mathrm{mg})$ & Standard & & Microorganism \\
\hline 20 & 26 & $\mathrm{G}+$ & Bacillus subtilus \\
17 & 25 & $\mathrm{G}-$ & Escherichia coli \\
21 & 26 & $\mathrm{G}-$ & Pseudomonas aeuroginosa \\
21 & 21 & $\mathrm{G}+$ & Staphylococcus aureus \\
20 & 27 & $\mathrm{G}+$ & Streptococcus faecalis \\
20 & 28 & $\mathrm{G}-$ & Neisseria gonorrhoeae \\
\hline
\end{tabular}


Food packaging materials depend on polysaccharides, proteins or lipids, so I chose ulvan as an edible and safe polysaccharides for active food packaging, but in general, all polysaccharides are hydrophilic and may cause some problems in food packaging to isolate the product from abiotic effects, therefore I decided to use eco-friendly green synthesized silver nanoparticles to be mediated in these films for the first time with ulvan and improve films properties of the film where the films exhibited good physical properties, have antioxidant and antibacterial activities. Therefore I recommend using these films in food packaging by coating on packaging materials such as glass, plastic, aluminum, foils, tinplate, paper or dipping those packaging materials in these bio-nanocomposite films to control gases diffusion, light oxidation and extend the lifetime of various packaged food and control food safety and food quality (Ravichandran, 2010).

\section{Conclusion}

Packaging food is an important function of food processing, because it controls the shape, physical and chemical properties of packages and it should increase shelf-life and food safety across long distances from production. The packages should act as barriers to gases and protect the packaged foods against the microbes and oxidants caused by harmful Ultraviolet rays. In this study I would like to highlight the production of cheap, new, non-toxic and eco-friendly bio-nonocomposite films using for the first time $1 \mathrm{~m} \mathrm{M}$ of green synthesized silver nanoparticles (Ag-NPs), using U. lactuca, incorporated into different concentrations (3, 6 and $12 \%$, $\mathrm{w}-\mathrm{v})$ of ulvan polysaccharides that extracted from $U$. lactuca by hot water-extraction and ethanol-precipitation and characterized by FT-IR spectroscopy. The biosynthesis of Ag-NPs was proven by UV-VIS, SEM and TEM analyses. The formed bio-nanocomposite films were chemically characterized by FTIR-ATR spectroscopy and TEM analysis and their physical properties were further determined such as contact angle $\left(70.833^{\circ}, 81.066^{\circ}\right.$ and $109.066^{\circ}$ respectively), barrier to water vapor permeability $(1.18 \pm 0.07,0.9 \pm 0.09$ and $0.55 \pm 0.1\left(10^{-8} \mathrm{~g} \mathrm{~mm} \mathrm{~cm}^{-2} \mathrm{~h}^{-1} \mathrm{~Pa}^{-1}\right)$ respectively) and film thickness $(0.01,0.03$ and $0.08 \mathrm{~mm}$ respectively). The formed films showed also good antimicrobial properties against several gram positive and gram negative bacteria that caused corruption of packaged foods such as packaged fruits, fish, vegetables, meat, poultry, fish, bakery and dairy products and showed also a good antioxidant activity with $\mathrm{IC}_{50}=1.128$ $\mu \mathrm{g} / \mathrm{ml}$. From previous obtained and confirmed results, the bio-nanocomposite films should be used in food packaging where it may increase the shelf life of packaged foods, food safety and food quality without harm as previous used packaging materials. In the near future, these formed films will be applied to different packaging materials and foods in vivo. We should expect a series of modern and non-toxic bio-nanocomposite films for food packaging.

\section{Acknowledgement}

The author expresses deep appreciation to a Professor of Microbiology and Phycology at the Faculty of Science at the University of Zagazig, who helped in the identification and classification of $U$. lactuca.

\section{Funding Sources}

The author(s) received no financial support for the research, authorship and/or publication of this article.

\section{Ethics}

This article is original and contains unpublished material. The corresponding author confirms that all of the other authors have read and approved the manuscript and no ethical issues involved.

\section{References}

Abd El-Galil, E. R., \& Amin, H. H. (2017). Evaluate adding green seaweed to different rations by In vitro gas production technique. New York Science journal, 10(8), 150-157.

Abreu, A. S., Oliveira, M., de Sá, A., Rodrigues, R. M., Cerqueira, M. A., Vicente, A. A., \& Machado, A. V. (2015). Antimicrobial nanostructured starch based films for packaging. Carbohydrate Polymers, 129, 127-134.

Ahmed, S., \& Ali, W. (Eds.). (2020). Green Nanomaterials: Processing, Properties and Applications (Vol. 126). Springer Nature.

Amin, H. H. (2019). Ulva lactuca as a cheap and safe biopesticide in fields and its chemical composition (in vitro). Egyptian Journal of Aquatic Biology and Fisheries, 23(5 (Special Issue)), 415-428.

Amin, H. H. (2020a). Biosynthesized silver nanoparticles using Ulva lactuca as a safe synthetic pesticide (in vitro). Open Agriculture, 5(1), 291-299.

Amin, H. H. (2020b). Ulvan as A New Trend in Agriculture, Food Processing and Medicine. Asian Journal of Fisheries and Aquatic Research, 47-54.

Amin, H. H., \& Abdelreheem, M. A. T. (2020). Comparative Effect of Ulvan and Biosynthesized Silver Nanoparticles on Different Cell Lines Cytotoxicity and Gene Expression. 
Amin, H. H., El-Sayed, A. B., Ramadan, K. M. A., Moussa, Z. A., \& Moawad, F. G. (2015). Evaluation of biological activity of extracts from different species of algae. Environ. Sci, 10(1), 281-297.

Azlin-Hasim, S., Cruz-Romero, M. C., Morris, M. A., Cummins, E., \& Kerry, J. P. (2015). Effects of a combination of antimicrobial silver low density polyethylene nanocomposite films and modified atmosphere packaging on the shelf life of chicken breast fillets. Food Packaging and Shelf Life, 4, 26-35.

Bauer, A. W. (1966). Antibiotic susceptibility testing by a standardized single disc method. Am J clin pathol, 45, 149-158.

Cano, A. I., Chiralt, A., \& González-Martínez, C. (2018). Silver Composite Materials and Food Packaging. Composites Materials for Food Packaging, 123.

Casariego, A. B. W. S., Souza, B. W. S., Cerqueira, M. A., Teixeira, J. A., Cruz, L., Díaz, R., \& Vicente, A. A. (2009). Chitosan/clay films' properties as affected by biopolymer and clay micro/nanoparticles' concentrations. Food Hydrocolloids, 23(7), 1895-1902.

Francis, R. R., Ali, H. M., Sarwat, M. I., \& Shahin, H. H. (2006). Synthesis and pesticidal activity of some cyclic organophosphorus compounds. Annals of Agricultural Science (Cairo), 51(2), 349-358.

Guidara, M., Yaich, H., Benelhadj, S., Adjouman, Y. D., Richel, A., Blecker, C., ... \& Garna, H. (2020). Smart ulvan films responsive to stimuli of plasticizer and extraction condition in physicochemical, optical, barrier and mechanical properties. International Journal of Biological Macromolecules, 150, 714-726.

Gupta, R. K., Dudeja, P., \& Minhas, A. S. (2017). Food Safety in the 21st Century. Public Health Perspective, 1 .

Hussein, U. K., Mahmoud, H. M., Farrag, A. G., \& Bishayee, A. (2015). Chemoprevention of diethylnitrosamine-initiated and phenobarbitalpromoted hepatocarcinogenesis in rats by sulfated polysaccharides and aqueous extract of Ulva lactuca. Integrative cancer therapies, 14(6), 525-545.

Khalifa, K. S., Hamouda, R. A., Hanafy, D., \& Hamza, A. (2016). In Vitro Antitumor activity of silver nanoparticles biosynthesized by marine algae. Digest Journal of Nanomaterials and Biostructures, 11(1), $213-221$.

Kumar, S., \& Thakur, K. S. (2020). Active packaging technology to retain storage quality of pear cv."Bartlett" during shelf-life periods under ambient holding after periodic cold storage. Packaging Technology and Science, 33(7), 239-254.
Lahaye, M., \& Robic, A. (2007). Structure and functional properties of ulvan, a polysaccharide from green seaweeds. Biomacromolecules, 8(6), 1765-1774.

Liebowitz, L. D., Ashbee, H. R., Evans, E. G. V., Chong, Y., Mallatova, N., Zaidi, M., ... \& Global Antifungal Surveillance Group. (2001). A two year global evaluation of the susceptibility of Candida species to fluconazole by disk diffusion. Diagnostic microbiology and infectious disease, 40(1-2), 27-33.

Matar, M. J., Ostrosky-Zeichner, L., Paetznick, V. L., Rodriguez, J. R., Chen, E., \& Rex, J. H. (2003). Correlation between E-test, disk diffusion and microdilution methods for antifungal susceptibility testing of fluconazole and voriconazole. Antimicrobial agents and chemotherapy, 47(5), 1647-1651.

Meshhal, A. M. A. (2018). Dietary Aspects of Green Marine Algae (Ulva lactuca) as a Potential Source of Natural Fatty acids. The Canadian Journal of Clinical Nutrition, 6(2), 75-83.

Moura, M. R. D., Mattoso, L. H. C., \& Zucolotto, V. (2012). Development of cellulose-based bactericidal nanocomposites containing silver nanoparticles and their use as active food packaging. Journal of Food Engineering, 109, 520-524.

National Committee for Clinical Laboratory Standards. (1993a). Methods for dilution antimicrobial susceptibility tests for bacteria that grow aerobically. Approved standard M7-A3. Villanova, PA: National Committee for Clinical Laboratory Standards.

National Committee for Clinical Laboratory Standards. (1993b). Performance standards for antimicrobial disk susceptibility tests. Approved standard M2-A5. Villanova, PA: National Committee for Clinical Laboratory Standards.

National Committee for Clinical Laboratory Standards. (2003). Method for antifungal disk diffusion susceptibility testing of yeast: proposed guideline M44-P. Wayne, PA, USA: NCCLS.

Nile, S. H., Baskar, V., Selvaraj, D., Nile, A., Xiao, J., \& Kai, G. (2020). Nanotechnologies in Food Science: Applications, Recent Trends and Future Perspectives. Nano-Micro Letters, 12(1), 45.

Nunes, M. R., Castilho, M. D. S. M., de Lima Veeck, A. P., da Rosa, C. G., Noronha, C. M., Maciel, M. V., \& Barreto, P. M. (2018). Antioxidant and antimicrobial methylcellulose films containing Lippia alba extract and silver nanoparticles. Carbohydrate polymers, 192, 37-43.

Oliani, W. L., Komatsu, L. G. H., Lincopan, N., Rangari, V. K., Lugao, A. B., \& Parra, D. F. (2016, October). Processing and antimicrobial efficacy of polypropylene/montmorillonite/silver nanocomposites as food packaging films. In AIP conference proceedings (Vol. 1779, No. 1, p. 040008). AIP Publishing LLC. 
Pfaller, M. A., Burmeister, L., Bartlett, M. S., \& Rinaldi, M. G. (1988). Multicenter evaluation of four methods of yeast inoculum preparation. Journal of clinical microbiology, 26(8), 1437-1441.

Ravichandran, R. (2010). Nanotechnology applications in food and food processing: innovative green approaches, opportunities and uncertainties for global market. International Journal of Green Nanotechnology: Physics and Chemistry, 1(2), P72-P96.

Rivas-Garcia, T., Murillo-Amador, B., Nieto-Garibay, A., Chiquito-Contreras, R. G., Rincon-Enriquez, G., \& Hernandez-Montiel, L. G. (2018). Effect of Ulvan on the Biocontrol Activity of Debaryomyces hansenii and Stenotrophomonas rhizophila against Fruit Rot of Cucumis melo L. Agronomy, 8(12), 273.
Shalaby, S. M., \& Amin, H. H. (2018). Red Cabbage and Turmeric Extracts as Potential Natural Colors and Antioxidants Additives in Stirred Yogurt. J Prob Health, 6, 206.

Shalaby, M. S., \& Amin, H. H. (2019). Potential using of ulvan polysaccharides from Ulva lactuca as a prebiotic in symbiotic yogurt production. J Prob Health, 7(1), 1-9.

Yu-Qing, T., Mahmood, K., Shehzadi, R., \& Ashraf, M. F. (2016). Ulva lactuca and its polysaccharides: Food and biomedical aspects. Journal of Biology, Agriculture and Healthcare, 6(1), 140-151. 